\title{
CLIMATOLOGIA E DESASTRES AMBIENTAIS: A DEMANDA DOS RECURSOS PÚBLICOS APÓS O ESPETÁCULO MIDIÁTICO ${ }^{1}$
}

\author{
Climatology and environmental disasters:
}

The demand of public funds after the media spectacle

\author{
Edson Soares Fialho \\ Professor Adjunto II do Departamento de Geografia da UFV \\ Doutor em Geografia Física pela Universidade de São Paulo (USP). \\ fialho@ufv.br
}

Artigo recebido em 31/03/2013 e aceito para publicação em 28/07/2013

DOI: 10.12957/tamoios.2013.5459

Resumo

Diante dos prejuízos econômicos e humanos desencadeados pelos eventos climáticos extremos o governo Federal criou-se uma entidade denominada Defesa Civil, responsável pelo gerenciamento dos desastres naturais. Neste sentido, este trabalho busca analisar o caminho dos recursos públicos após eventos climáticos extremos, destacando Minas Gerais. Para isto, recorreu-se aos portais das Secretarias de Defesa Civil Nacional, a CEDEC-MG e Transparência Pública. A partir da correlação dos dados de registros de situação de emergência, Estado de Calamidade Pública e liberação de recursos públicos, pode-se dizer que a Defesa Civil de Minas Gerais presta apoio aos municípios para que estes se prepararem para suportar os eventos climáticos. Deste modo, pode-se dizer que mesmo com a CEDEC/MG amparando os municípios, ainda é notável o descaso do Poder Público Local que não observa os passos e prazos a serem seguidos para decretar a situação de emergência ou Estado de calamidade pública, que pelo menos garante a possibilidade de acesso aos recursos públicos estaduais e federais.

Palavras-chaves: Defesa Civil, Minas Gerais, Recursos.

Abstract In the face of economic and human losses triggered by extreme weather events the Federal Government created an entity called the Civil Defense, responsible for the management of natural disasters. In this sense, this paper seeks to analyse the way public funds after extreme weather events, highlighting the State of Minas Gerais. For this, been to the very gates of the secretariats of National Civil Defence, the CEDEC-MG and Transparency Public Pictures. From the correlation of data from records of emergency situation, the State of Public Calamity and release of public resources, it can be said that the Civil Defense of Minas Gerais in the Southeast region provides support to municipalities so that they prepare to withstand the climatic events. In this way, it can be said that even with the CEDECMG supporting the municipalities, is still remarkable disregard Local public power that does not observe the steps and deadlines to be followed to enact the emergency or State of public calamity, which at least ensures the possibility of access to public State and federal resources.

Keywords: Civil Defense, Minas Gerais, resources. 


\section{PRÓLOGO}

O campo da climatologia é de nosso interesse desde o início da graduação, quando começamos a trabalhar como bolsista de iniciação científica, sob orientação da Professora Ana Maria de Paiva Macedo Brandão (UFRJ). Desde então, a abordagem é direcionada para a discussão relacionada aos problemas ambientais decorrentes das transformações das naturais (Glaciação e Interglaciação) ou antrópicas (alteração da superfície terrestre), que interferem no processo de evolução da paisagem, produto da relação humana e natural. Porém, segundo Lima e Zanella (2011) a composição da paisagem geográfica tem o clima como um dos elementos naturais de primeira ordem.

Entretanto, com o advento da urbanização e de novos processos de incorporação de espaços rurais, os processos sociais acabam por se sobrepor às dinâmicas da natureza. Nesse contexto, a complexidade inerente a produção da paisagem, acaba por ampliar o número de ocorrência de impactos ambientais decorrentes de fenômenos climáticos extremos.

Dentro desta lógica, hoje, com o desenvolvimento de nossas atividades de pesquisa, juntamente com a equipe de bolsistas e voluntários, o Laboratório de Biogeografia e Climatologia (BIOCLIMA-UFV), busca uma perspectiva que integradora, que contemple as ações humanas no processo de reconstrução dos ambientes urbanos e rurais, a partir do acompanhamento das tomadas de decisões de atores políticos e comunitários ao longo das esferas de poder e não apenas a identificação dos desastres associados associados a sistemas climáticos excepcionais e seus impactos. Até mesmo porque, na região sudeste, desde 1948, com os estudos de Sternberg (1949), no vale do rio Paraíba do Sul, tais desastres são retratados e abordados de maneira sistemática quase que anualmente, porém em locais diferentes.

Esta postura, por sua vez, permite compreender a dimensão política das ações dos atores sociais envolvidos, bem como auxiliar na dismistificação das repercurssões sociais e econômicas dos desastres ambientais, que não são consequência da ocorrência de um fenômeno natural. Mas, sim de uma ação equivocada no processo de incorporação de paisagens à dinâmica social, que vem sendo acompanhada pelos noticiários de jornais, que retratam de maneira descontinua a sequência dos fatos e dos impactos consequentes, relacionados aos eventos episódicos concentrados de chuva e demais desastres ambientais (estiagem, seca, granizos, vendavais, ciclones, tornados, incêndios florestais, movimentos de massa, erosão laminar, erosão fluvial, erosão marinha, inundação brusca e inundação gradual), gerando uma sensação de vazio recorrente, pois, à medida que o problema do ano anterior, ainda não resolvido, mas "esquecido", outro surge ganhando proporções cada vez maiores.

Nesse contexto, o presente trabalho apresentará alguns resultados da pesquisa, intitulada: Impacto pluvial e organização do território: Compreendendo o percurso dos recursos de reconstrução para os municípios mineiros atingidos pelas enchentes/secas entre 2006 e 2009 e suas repercussões socioeconômicas na paisagem, que procura compreender o caminho dos recursos federais e estaduais até chegar aos municípios afetados pela seca e enchente e sua empregabilidade no processo da reorganização do território. Para efeito didático, o recorte espacial adotado será o Estado de Minas Gerais, destacando em algum momento o alto vale do rio Doce. 


\section{INTRODUÇÃO}

A repercussão das chuvas de verão na região sudeste nos últimos anos vem alarmando a todos, devido aos impactos em áreas inapropriadas, que não possuem nenhuma proteção contra a ação erosiva da gota da chuva e muito menos uma infraestrutura adequada para o escoamento superficial das águas, o que acaba por gerar verdadeiras cachoeiras em ruas com declividade.

As chuvas torrenciais cada vez mais ceifam vidas. No entanto, parece ser notável que nos últimos anos, os desastres tenham aumentado, em razão do crescimento urbano (BARRETO, 2012) ou estão sendo mais noticiados (MAIA; PITTON, 2009).

$\mathrm{O}$ crescimento do número de alagamentos, muitas vezes atrelados à intensidade da chuva e o insuficiente escoamento da água, nas manchas urbanas, agravam os problemas e aumenta as vulnerabilidades do espaço, principalmente, na região sudeste, onde a climatologia é muito diversificada (SANT’ANNA NETO, 2005), em razão de algumas razões, tais como: a) localização latitudinal da região, considerada de transição entre climas quentes de latitudes baixas e clima tropical de altitude e b) as topografias associadas à circulação atmosférica contribuem muito para que ocorra esta concentração pluvial, principalmente no verão quando há maior atuação da Zona de Convergência do Atlântico Sul com agregação de outros sistemas atmosféricos. A Zona de Convergência do Atlântico Sul, de acordo com Abreu (1998), é fundamental para que aconteça uma maior concentração de núcleos de condensação e, consequentemente, um maior índice de precipitação no verão da região Sudeste.

No entanto, por mais que estudos e pesquisas comprovem que o volume de pluviosidade elevado na região sudeste ocorre devido à combinação entre a topografia associada à dinâmica dos sistemas atmosféricos. A repercussão demonstrada pela mídia escrita de caráter superficial e corriqueiro, com capas de grande apelo visual (Figura 1), não é o que é esperado, muito pelo contrário. As consequências são além da capacidade de suporte do espaço, mesmo com totais pluviométricos não superior a 40mm em 30 minutos, conforme Brandão (1992 e 1997) verificou para a cidade do Rio de Janeiro.

Em relação à criação das defesas civis, cabe destacar que no Brasil o sistema de monitoramento e gereciamento dos desastres se consolidam após o ano de 1978/1979, período em que a bacia do rio doce foi extremamente impactada e Minas Gerais foram amplamente afetados (GONTIJO; ASSIS, 1997).

A partir disso, procedimentos foram adotados para serem utilizados em situação de vulnerabilidade. Inicialmente, o município que não consegue por suas próprias forças contornar a situação, poderá utilizar de instrumentos legais que permitem ao município solicitar auxílio financeiro, tanto ao Estado quanto ao Governo Federal. Neste caso, o município poderá decretar Situação de Emergência (SE) ou Estado de Calamidade Pública (ECP).

Estes decretos foram regulamentados em 1999, através do estabelecimento de critérios e procedimentos para a decretação dessas duas possibilidades ${ }^{2}$, que são adotados por todos os órgãos de Defesa Civil, válido em todo território brasileiro. Portanto:

“...A decretação de Situação de Emergência ou de Estado de Calamidade Pública não é, e não deve ser feita com o objetivo único de recorrer aos cofres do Estado ou da União, para solicitar recursos financeiros. A decretação significa a garantia plena da ocorrência de uma situação normal, em uma área do município, que determinou a necessidade de o Prefeito declarar Situação de Emergência ou Estado de Calamidade Pública, para ter efeito "na alteração dos processos de governo e da ordem jurídica, no território considerado, durante o menor 
prazo possível, para restabelecer a situação de normalidade..." (SECRETARIA NACIONAL DE DEFESA CIVIL, 2009).
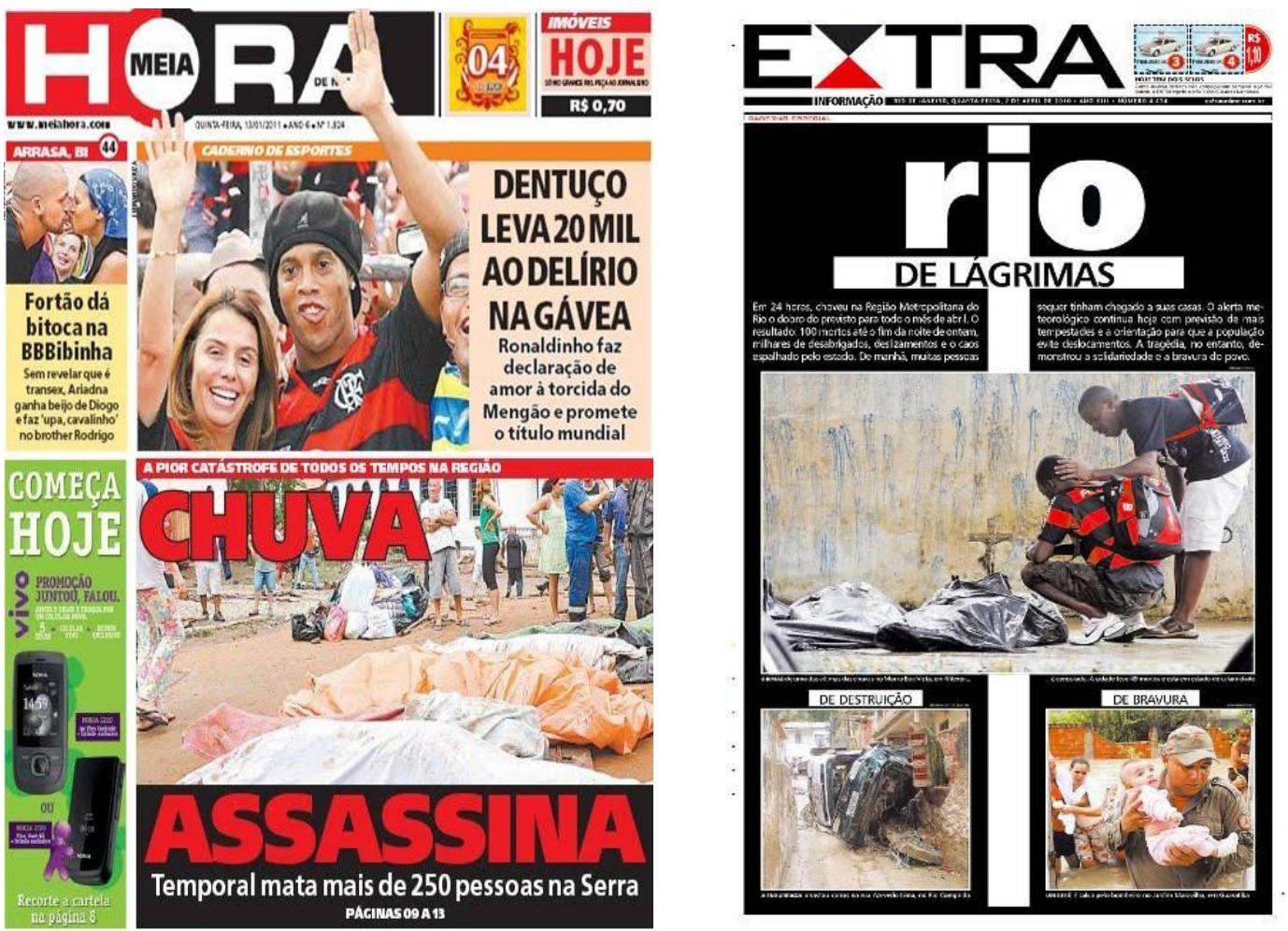

Figura 1. Imagens de vítimas mortas no chão enroladas em sacos, intercaladas com outras notícias de destaque na parte superior (Jornal Meio Hora - 13/01/2011) e o Extra (07/04/2010), destaca em capa inteira a morte de milhares de pessoas, bem como a luta pela vida nas mãos dos bombeiros.

Fonte: Fialho (2011).

$\mathrm{Na}$ atualidade, mesmo diante do avanço tecnológico que busca o conhecimento das forças da natureza, observa-se que as sociedades mantêm-se indefesas frente aos eventos naturais extremos, que ocasionam grandes perdas e prejuízos à população.

De acordo com Gonçalves (2003), no Brasil os eventos catastróficos se relacionam à natureza climática, ou seja, são fenômenos relacionados às variações bruscas de temperatura, oscilações hídricas, que causam impacto no meio ambiente, à população e à economia do país.

Tais episódios ocorrem com mais frequência nas regiões Sul e Sudeste, onde se tem a maior concentração populacional do país. Aliado a isto, tem-se os problemas relacionados à precariedade da infraestrutura no que tange as habitações nas margens de rios e principalmente nas encostas, o que denota sérias consequências durante o período chuvoso.

Infelizmente, no Brasil estes problemas só vêm à tona na época das chuvas, passado este período, os mesmos são esquecidos pelo Poder Público. Contudo, quando a população tem consciência das consequências, e desse modo, participa da prevenção e preparação desse tipo de evento, a mesma é poupada dos graves prejuízos e danos.

Assim, os países que investem em prevenção destinam menos recursos financeiros para ações de contenção de impactos emergenciais, perdendo menos vidas humanas, que os países que priorizam o atendimento de resposta aos desastres, como é o caso do Brasil. 
De tal modo, em decorrência da constância deste tipo de evento, bem como os prejuízos causados, criou-se a entidade denominada Defesa Civil, no âmbito Federal, Estadual e Municipal, sendo este último criado de acordo com o interesse do poder público local.

O objetivo deste órgão é evitar ou minimizar os desastres, de maneira a restabelecer a normalidade social. Para isto, é necessário um conjunto de ações preventivas, no entanto, em muitos casos essas ações têm caráter de urgência e assistenciais.

Por outro lado, os desastres aumentam significativamente a dívida social, que em grande parte aflige os indivíduos de menor poder aquisitivo, em municípios com pouca capacidade financeira para se restabelecerem frente às consequências destes desastres.

Deste modo, estabeleceram-se estratégias que visam amenizar estes danos e prejuízos de ordem econômica e social, através do mecanismo de decretação da Situação de Emergência (SE) ou Estado de Calamidade Pública (ECP), como forma de auferir recursos financeiros do Governo Federal e Estadual. Estes recursos liberados pela União ou pelo Estado, segundo Fialho e Coelho (2011) têm como finalidade única amenizar os prejuízos materiais dos municípios atingidos pelos eventos naturais (seca, estiagem, enchente/inundação, enxurrada, alagamento, granizo, vendavais, tempestades, escorregamento/deslizamento).

Em 1999, estabeleceram-se critérios e procedimentos para a decretação dessas duas possibilidades legais a serem adotados por todos os órgãos de Defesa Civil. Assim, faz-se necessário analisar os fatores preponderantes que se referem à intensidade dos danos (humanos, materiais e ambientais) e a ponderação dos prejuízos (sociais e econômicos) sob a ótica da coletividade; e os fatores agravantes que dizem respeito à ocorrência de desastres secundários, ao despreparo da administração local ao grau de vulnerabilidade do cenário e da comunidade e ao padrão evolutivo do desastre (FIALHO, 2012a).

Em Minas Gerais, o Sistema Estadual de Defesa Civil (Figura 2) pauta-se em uma estrutura governamental de planejamento e execução de medidas de Defesa Civil, que objetiva coordenar esforços de todos os órgãos estaduais, com os demais órgãos públicos e privados, e com a comunidade em geral, tendo como finalidade prevenir as consequências nocivas dos eventos desastrosos e socorrer as populações atingidas por esses mesmos eventos com emprego racional de recursos e adequado controle da emergência.

Deste modo:

“...O atual sistema de Defesa Civil favorece a articulação das entidades públicas e a integração de forças e recursos comunitários. As Regiões da Polícia Militar, que constituem as Regionais de Defesa Civil - REDEC - são as bases de sustentação das atividades desenvolvidas pela CEDEC em todo território mineiro. Assim, cada Comandante da Polícia Militar, no interior do Estado, são os Regionais de Defesa Civil, e atuam em todos os municípios de sua circunscrição. Estas ações dos Regionais têm estreito relacionamento com a Defesa Civil dos municípios, precedem as ações do Estado e da União. Quanto mais ampliada a rede do Sistema, maiores serão as possibilidades de êxito e de participação comunitária, sobretudo no campo preventivo (CEDEC/MG, 2009)....". 


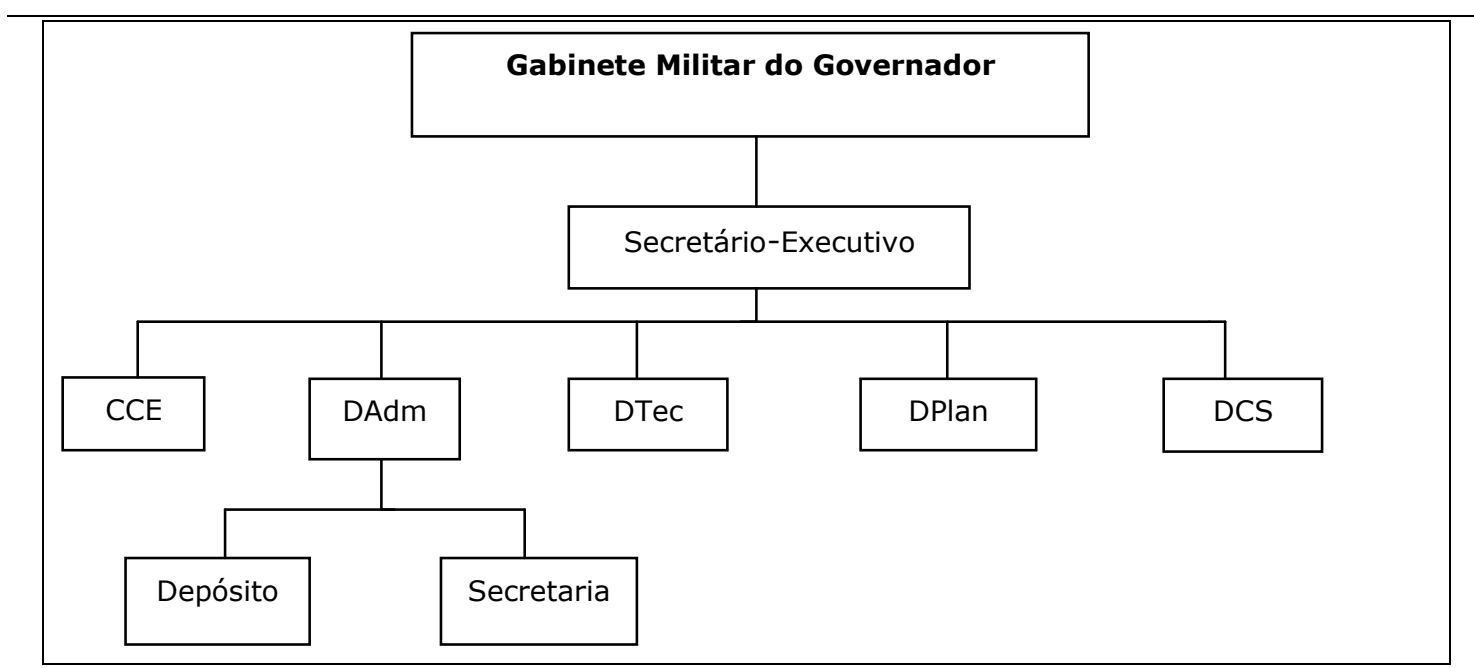

CCE-Centro de Controle de Emergências; DAdm - Diretor Administrativo; DTec - Diretor

Técnico; DPlan - Diretor de Planejamento; DCS - Diretor de Comunicação Social.

Figura 2. Organograma da CEDEC/MG.

Fonte: Cedec/MG (2009).

No levantamento realizado em 11 de abril de 2010, Nascimento e Fialho (2010), verificaram que o Estado de Minas Gerais possui 667 Coordenadorias Municipais de Defesa Civil - COMDEC's. Hoje, março de 2013, há 708 em uma malha de 853 municípios e uma rede de depósitos avançados de material emergencial localizada em doze Batalhões da Polícia Militar (PM) no interior do Estado. A localização destes depósitos nos Batalhões deve-se ao fato da PM ser o único órgão presente em todos os municípios. Desse modo:

[...] No Estado a Defesa Civil faz parte do Gabinete Militar do Governador, então o Gabinete Militar do Governador, além da segurança do Governador e do vice, uma das ações é a Defesa Civil do Estado. Quem trabalha na Defesa Civil do Estado são os Policiais Militares, Bombeiros Militares e Civis contratados pelo Estado ou efetivos [...] O Coronel chefe do Gabinete Militar é o Coordenador Estadual de Defesa Civil, que hoje é o Coronel Eduardo Mendes, porque o chefe de Gabinete Militar é o único secretário que cumprimenta o Governador todo dia de manhã, é um ato solene do chefe de Gabinete, e quem trabalha na Defesa Civil tem que ter acesso ao Governante a qualquer momento, não pode ter burocracia não pode ter partido político, nem nada, é chegar e dizer ao, Governador o acontecido e tomarmos as medidas cabíveis [...] (ABREU, CEDECMG, 02/09/2009) apud NASCIMENTO, 2010).

Além disso, é necessário enfatizar que a Defesa Civil trabalha com alguns conceitos chave que são de extrema importância frente aos eventos climáticos. Assim, define que:

Desaparecidos, até que se prove o contrário, são pessoas desaparecidas, em circunstâncias de desastres, são consideradas vivas, porém em situação de risco de morte iminente e em locais inseguros e perigosos, 
demandando esforço de busca e salvamento para serem encontradas e resgatadas com o máximo de urgência [...]

Deslocados, são pessoas que, por motivo de desastre, [...] são compelidos a migrar das regiões que habitam para outras que lhes sejam mais propícias $[\ldots]$

Desabrigados são pessoas cujas habitações foram destruídas ou danificadas por desastres, ou estão localizadas em áreas de risco iminente de destruição, e que necessitam de abrigos temporários para serem alojadas.

Desalojados, pessoas cujas habitações foram danificadas ou destruídas, mas que, não necessariamente, precisam de abrigos temporários. Nem todas as pessoas que foram desalojadas de suas habitações, em circunstâncias de desastres, demandam abrigos temporários e são classificadas como desabrigados. É normal que, nessas circunstâncias, um grande número de famílias desalojadas hospede-se em casas de amigos e parentes, reduzindo a demanda de abrigos temporários (SECRETARIA NACIONAL DE DEFESA CIVIL, 2009).

Em decorrência dos desastres, quando o município não consegue por suas próprias forças contornar a situação, há instrumentos legais que permitem a este pedir ajuda tanto ao nível de Estado, quanto ao nível Federal, na medida em que, decrete Situação de Emergência (SE) ou Estado de Calamidade Pública (ECP). Todavia, tais decretos obedecem a critérios e procedimentos, conforme demonstrado na Tabela 1.

Antes do Prefeito decretar a situação de anormalidade, é preciso que o mesmo comunique a ocorrência do evento à Defesa Civil Estadual e a Secretaria Nacional de Defesa Civil, localizada em Brasília.

Isto deve ser comunicado através do preenchimento do formulário denominado Notificação Preliminar de Desastre - NOPRED Este formulário deve ser preenchido e enviado em um prazo máximo de 12 horas, após a ocorrência do desastre. A NOPRED é um resumo, muito simples, no entanto, fundamental no que tange apoio ao Município. O documento mais importante é a Avaliação de Danos - AVADAN³. Este documento é uma radiografia do desastre, que deve ser preenchido e enviado em um prazo máximo de 5 dias; fundamenta $o$ decreto de SE ou ECP do local afetado, que é de competência do Prefeito.

Após este passo, o decreto de SE ou ECP deve ser enviado à Defesa Civil Estadual, sendo obrigatório o envio dos seguintes anexos: AVADAN; mapa ou croqui da área afetada pelo desastre; fotos do local atingido; ocorrência Policial/Bombeiro; laudos complementares de órgãos presentes no município, como do Instituto Estadual de Florestas - IEF, Empresa de Assistência Técnica e Extensão Rural do Estado de Minas Gerais - EMATER, entre outros. Estes anexos são de fundamental importância, e devem estar preenchidos adequadamente, pois somente assim será homologado pelo Governo de Estado. 
Tabela 1. Critérios Estabelecidos para Decretação de Situação de Emergência (SE) ou Estado de Calamidade Pública (ECP)

\section{Critérios Preponderantes}

Danos Humanos

\begin{tabular}{cc}
\hline Criticidade 1 & Criticidade 2 \\
Feridos graves & Enfermos \\
Desaparecidos & Feridos leves \\
Deslocados & Desalojados \\
Desabrigados & \\
Mortos & \\
\hline Danos Materiais Destruídos/Danificados \\
\hline prioridade 1 & prioridade 2 \\
\hline Instalações públicas de saúde & Instalações particulares de saúde \\
Residenciais populares & Instalações part. de ensino \\
Instalações públicas de ensino & Instalações rurais/ nd/ com/ prest. Serv \\
Obras de infraestrutura pública & Residenciais classes + favorecidas \\
Outras instalações serv. essenciais & \multicolumn{2}{c}{ Danos Ambientais } \\
\hline \multicolumn{2}{c}{ 1. Contaminação e/ou poluição das fontes de água } \\
2. Contaminação, poluição e/ou degradação do solo \\
3. Degradação da biota e redução da biodiversidade \\
4. Poluição do ar atmosférico
\end{tabular}

\section{Ponderação dos Prejuízos}

\section{Prejuízos Econômicos}

\begin{tabular}{cc}
\hline Nível I & Prejuízo $\leq 5 \%$ PIB \\
Nível II & $5 \%<$ Prejuízo $\leq 10 \%$ PIB \\
Nível III & $10 \%<$ Prejuízo $\leq 30 \%$ PIB \\
Nível IV & Prejuízo > 30\% PIB \\
\hline \multicolumn{2}{c}{ Prejuízos Sociais } \\
\hline prioridade 1 & prioridade 2 \\
\hline Assistência médica primária e hospitalar & Geração e distribuição de energia elétrica \\
Emergências médico-cirúrgicas & Telecomunicações \\
Abastecimento de água potável & Distr. combustíveis/ também doméstico \\
Esgoto sanitário & ---- \\
Limpeza urbana / coleta de lixo & ---- \\
Controle de pragas e de vetores & ---- \\
Vigilância sanitária & ---- \\
\hline
\end{tabular}




\section{Critérios Agravantes}

Desastre Nível I - Pequena intensidade ou acidente.

\begin{tabular}{lccc}
\hline \multicolumn{1}{c}{ Condicionantes } & Caracteriza & Critérios agravantes & $\begin{array}{c}\text { Situação } \\
\text { agravada }\end{array}$ \\
$\begin{array}{l}\text { 1. Facilmente suportável } \\
\text { 2. Danos pouco importantes }\end{array}$ & $\begin{array}{c}\text { situação } \\
\text { 3. Prejuízos pouco vultosos }\end{array}$ & $\begin{array}{c}\text { Não há fatores } \\
\text { agravanal }\end{array}$ & NÃO \\
\hline
\end{tabular}

\section{Desastre Nível II - Média intensidade.}

\begin{tabular}{|c|c|c|c|}
\hline Condicionantes & Caracteriza & Critérios agravantes & $\begin{array}{c}\text { Situação } \\
\text { agravada }\end{array}$ \\
\hline 1. Suportável e superável & & - Desastre secundário & \\
\hline $\begin{array}{l}\text { 2. Danos de alguma } \\
\text { importância } \\
\text { 3. Prejuízos significativos }\end{array}$ & $\begin{array}{l}\text { Situação } \\
\text { anormal }\end{array}$ & $\begin{array}{l}\text { - Despreparo DC local } \\
\text { - Grau vulnerabilidade } \\
\text { - Padrão evolutivo }\end{array}$ & $\begin{array}{l}\text { S.E. } \\
\text { Situação de } \\
\text { Emergência }\end{array}$ \\
\hline
\end{tabular}

\begin{tabular}{|c|c|c|c|}
\hline \multicolumn{4}{|c|}{ Desastre Nível III - Grande intensidade. } \\
\hline Condicionantes & Caracteriza & Critérios agravantes & $\begin{array}{l}\text { Situação } \\
\text { agravada }\end{array}$ \\
\hline $\begin{array}{l}\text { 1. Suportável e superável, se a } \\
\text { comunidade estiver } \\
\text { preparada } \\
\text { 2. Danos importantes } \\
\text { prejuízos vultosos }\end{array}$ & $\begin{array}{l}\text { Situação de } \\
\text { emergência }\end{array}$ & $\begin{array}{l}\text { - Desastre secundário } \\
\text { - Despreparo DC local } \\
\text { - Grau vulnerabilidade } \\
\text { - Padrão evolutivo }\end{array}$ & $\begin{array}{c}\text { E.C.P. } \\
\text { Estado de } \\
\text { Calamidade } \\
\text { Pública }\end{array}$ \\
\hline \multicolumn{4}{|c|}{ Desastre Nível IV - Grande intensidade. } \\
\hline Condicionantes & Caracteriza & Critérios agravantes & $\begin{array}{c}\text { Situação } \\
\text { agravada }\end{array}$ \\
\hline $\begin{array}{l}\text { 1. Não suportável e não } \\
\text { superável sem ajuda } \\
\text { externa } \\
\text { 2. Danos muito } \\
\text { importantes } \\
\text { 3. Prejuízos muito } \\
\text { vultosos e consideráveis }\end{array}$ & $\begin{array}{c}\text { E.C.P. } \\
\text { Estado de } \\
\text { Calamidade } \\
\text { Pública }\end{array}$ & $\begin{array}{l}\text { - Casos excepcionais } \\
\text { previstos na } \\
\text { Constituição Federal } \\
\text { - Decreto do } \\
\text { Presidente da } \\
\text { República, ouvidos } \\
\text { os Conselhos da } \\
\text { República e de } \\
\text { Defesa Nacional. }\end{array}$ & $\begin{array}{c}\text { Estado de } \\
\text { defesa } \\
\text { (Art. 136) } \\
\text { Estado de sítio } \\
\text { (Art. 137) } \\
\text { Autorizado } \\
\text { pelo Congresso } \\
\text { Nacional }\end{array}$ \\
\hline
\end{tabular}

Fonte: Sistema Nacional de Defesa Civil (2013).

Tanto a NOPRED quanto o AVADAN devem ser preenchidos pelo Coordenador da COMDEC, quando os municípios a possuem, ou pelo Prefeito em caso de inexistência da COMDEC. Assim, estes são responsáveis pelas informações prestadas, podendo acarretar implicações jurídicas em caso de informações incorretas.

Já o decreto de SE ou ECP é assinado somente pelo Prefeito. É importante ressaltar que este decreto irá determinar o tempo de duração, além de especificar as áreas que serão abrangidas pela homologação. Em decorrência da evolução do desastre, o prazo de vigência do decreto pode variar entre 30, 60 e 90 dias, podendo ser prorrogado até 180 dias, o que implica a dispensa de licitação para a execução das obras de reconstrução. 
A homologação é de competência do Governador do Estado, porém, esta apenas ocorre se o AVADAN estiver correto. Ao fazer a homologação, o Governador está concordando com o decreto e colocando o Estado à disposição do Prefeito no que tange as obras de reconstrução, se tiver dinheiro. Assim, na disponibilidade de recursos terão prioridades os municípios que decretaram SE ou ECP. O reconhecimento à solicitação de SE ou ECP é de competência do Governo Federal. Este, por sua vez, é realizado através de ofício do Coordenador Estadual de Defesa Civil, juntamente com a homologação de reconhecimento do Estado (Figura 3); cópia da publicação do decreto do Governador no Diário Oficial do Estado; formulário do AVADAN; mapa ou croqui da área afetada pelo desastre, delimitando o local; fotos do local atingido; laudos, caso necessário; Boletim de ocorrência (PM/BM); parecer do órgão de coordenação do Sistema Nacional de Defesa Civil (SINDEC), em nível estadual, sobre a intensidade do desastre e sobre a coerência dos atos, em relação aos critérios estabelecidos pelo Conselho Nacional de Defesa Civil (CONDEC)

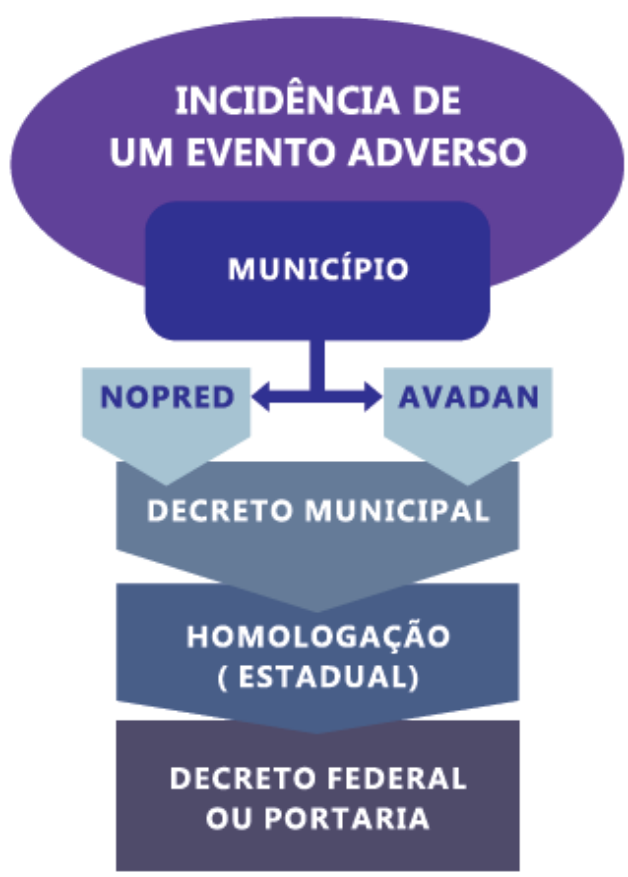

Figura 3. Organograma do processo de decretação de Situação de Emergência e Estado de Calamidade Pública dentro da estruturada da Defesa Civil Nacional.

Fonte: Atlas de Desastres Naturais de Minas Gerais (2012).

Posteriormente, o processo é enviado para a Defesa Civil Nacional que o analisará, caso a documentação esteja correta, o município será reconhecido. Neste caso o Governo Federal estará apto a liberar recursos para a reconstrução do município. Entretanto, a liberação de recursos para a reconstrução da área atingida pelo desastre é pautada na elaboração de projetos (plano de trabalho, meta, duração da obra).

Este recurso pode ser liberado pelo Governo Estadual através da homologação, e pelo Governo Federal através do reconhecimento. Quando o decreto é homologado ou reconhecido, o Prefeito pode angariar verbas de várias Secretarias e Ministérios com o apoio do Deputado Estadual ou Federal, desde que tenha bons projetos. Entretanto, segundo Fialho (2012b) a liberação deste recurso pode ser de 8 a 12 meses se o processo tramitar sem grandes problemas, mas caso ocorra pode ultrapassar a próxima temporada sazonal de fenômenos extremos. Por 
motivos que podem ser desde denúncias de corrupção até problemas processuais, como falta de documentação e instrução do processo, o que faz com que os órgãos fiscalizadores, como o Tribunal de Contas da União (TCU), possam solicitar mais detalhamentos do projeto, como ocorreu com as Prefeituras da região serrana do Rio de Janeiro.

Há também o recurso emergencial, que consiste em tudo aquilo que o Estado ajudou e/ou apoiou o município em decorrência do evento, como: sobrevoo da área afetada, cesta básica, colchão, cobertor, deslocamento da CEDEC/MG para auxiliar o município, máquinas do Departamento de Estradas de Rodagem para recuperar as estradas, entre outros. Este recurso é liberado de imediato, ou seja, assim que acontece o evento. Com base nestes passos a $\mathrm{CEDEC} / \mathrm{MG}$, divulga a cada ano o balanço das chuvas, conforme pode ser verificado na Tabela 2, onde se constata o grande número de municípios atingidos, não apenas pelas chuvas, mas pelas secas, no Estado de Minas, que assola, principalmente, a região norte.

Tabela 2. Balanço das Chuvas para o Estado de Minas Gerais.

\begin{tabular}{|c|c|c|c|c|c|c|c|}
\hline $\begin{array}{c}\text { BALANÇO DAS } \\
\text { CHUVAS }\end{array}$ & $2005 / 2006$ & $2006 / 2007$ & $2007 / 2008$ & $2008 / 2009$ & $2009 / 2010$ & 2010/2011 & 2011/2012 \\
\hline $\begin{array}{c}\text { Municípios } \\
\text { afetados }\end{array}$ & 152 & 316 & 121 & 276 & 120 & 216 & 273 \\
\hline \multicolumn{8}{|c|}{ Municípios que Decretaram Situação de Anormalidade } \\
\hline $\begin{array}{c}\text { Situação de } \\
\text { emergência (SE) }\end{array}$ & 69 & 208 & 42 & 213 & & & 239 \\
\hline $\begin{array}{c}\text { Estado de } \\
\text { calamidade } \\
\text { pública }(\mathrm{ECP})\end{array}$ & - & - & & - & & & \\
\hline \multicolumn{8}{|c|}{ Danos Humanos } \\
\hline Óbitos & 16 & 26 & 20 & 44 & 20 & 23 & 20 \\
\hline Feridos & 154 & 309 & 45 & 482 & 68 & 439 & \\
\hline Desabrigados & 6.100 & 14.744 & 4.345 & 11.630 & 2.406 & 4.303 & 9.594 \\
\hline Desalojados & 14.600 & 47.793 & 1.875 & 113.548 & 11.206 & 37.876 & 106.618 \\
\hline Desaparecidos & - & - & - & 1 & & & \\
\hline \multicolumn{8}{|c|}{ Danos Materiais } \\
\hline Casas destruídas & 1.181 & 1.521 & \begin{tabular}{|l|}
94 \\
\end{tabular} & 1.092 & & & \\
\hline Casas danificadas & 5.325 & 9.568 & 2.101 & 29.435 & & & \\
\hline Pontes destruídas & 212 & 702 & 24 & 419 & & & \\
\hline $\begin{array}{c}\text { Pontes } \\
\text { danificadas }\end{array}$ & 201 & 946 & 54 & 609 & & & \\
\hline
\end{tabular}

Fonte: Nascimento \& Fialho (2009); Fialho \& Coelho (2010) e Relatório da Defesa Civil de 2011/2012.

Porém, quando se observa a Tabela 3, constata-se o despreparo dos municípios mineiros no processo de reabilitação a ocorrência de desastres naturais, principalmente, quando se considera que em um universo de 121 municípios afetados no biênio 2007/2008, apenas 7 conseguiram ter homologado os seus processos enviados a Defesa Civil Estadual.

Tal discrepância pode ser explicada, com base na inobservância dos passos e prazos a serem seguidos e cumpridos, à ineficiência da COMDEC, e também ao descaso do Poder 
Público Local. Deve-se ressaltar que a liberação de recursos para a reconstrução não é imediata, podendo levar anos para o município usufruir do mesmo.

Este cenário pode causar sérias distorções, como publicado pelo jornalista Fábio Grellet, no Jornal o Estado de São Paulo, em 19 de março de 2013 (on-line), onde registrou que a cidade do Rio de Janeiro, embora tenha sido atingida em menor intensidade pelas chuvas do verão de 2011, recebeu mais investimentos públicos relacionados a obras de prevenção ou recuperação em desastres ambientais do que os municípios da região serrana do Rio de Janeiro, área mais afetadas pelo impacto das chuvas. Cabe destacar, que a liberação destes recursos obedece a um plano de gestão de previsão de projetos e gastos, que os municípios de maior capacidade técnica têm e, por isto, receberão sempre mais recursos. Tal lógica, por sua vez, ao longo do tempo cria uma distorção e amplia as vulnerabilidades dos municípios mais atingidos.

Tabela 3. Quantidade de municípios atingidos por desastres provocados Pelas chuvas no Estado de Minas Gerais no período de 2001 a 2011.

\begin{tabular}{|c|c|c|c|c|c|c|c|c|c|c|}
\hline Desastres & $\mathbf{2 0 0 1 /}$ & $\mathbf{2 0 0 2 /}$ & $\mathbf{2 0 0 3 /}$ & $\mathbf{2 0 0 4 /}$ & $\mathbf{2 0 0 5 /}$ & $\mathbf{2 0 0 6 /}$ & $\mathbf{2 0 0 7 /}$ & $\mathbf{2 0 0 8 /}$ & $\mathbf{2 0 0 9 /}$ & $\mathbf{2 0 1 0 /}$ \\
$\mathbf{0 2}$ & $\mathbf{0 3}$ & $\mathbf{0 4}$ & $\mathbf{0 5}$ & $\mathbf{0 6}$ & $\mathbf{0 7}$ & $\mathbf{0 8}$ & $\mathbf{0 9}$ & $\mathbf{1 0}$ & $\mathbf{1 1}$ \\
\hline $\begin{array}{c}\text { Municípios } \\
\text { atingidos }\end{array}$ & 239 & 261 & 218 & 234 & 152 & 316 & 121 & 276 & 120 & 216 \\
\hline $\begin{array}{c}\text { Processos } \\
\text { homologados }\end{array}$ & 169 & 136 & 105 & 50 & 20 & 158 & 7 & 100 & 29 & 97 \\
\hline
\end{tabular}

Disponível em http://mediaserver.almg.gov.br/acervo/887/724887.pdf. Acesso em 29mar 2013.

Ao contextualiza essa informação na escala temporal (Figura 4), representada pelo eixo x (horizontal), identifica-se que o cenário do Estado de Minas Gerais é crítico, pois o número de desastres naturais aumentou entre 1991-2000 e 2001-2010, como pode ser visto no eixo y (vertical), onde se observa o número absoluto de registros de desastres.

A primeira década (1991-2000) registra 14\% das ocorrências em comparação com os 86\% do período 2001-2010. Em relação à tipologia dos desastres naturais, as secas e a estiagem ocupam lugar de destaque para o período de 1991-2010, com 47\% das ocorrências, seguido por inundação brusca (22\%), inundação gradual (19\%) e outros (12\%).

Em entrevista realizada com o Major Abreu da Defesa Civil Estadual, obtida em Nascimento (2009), o mesmo enfatiza que a Coordenadoria Municipal de Defesa Civil (COMDEC) é o órgão mais importante na estrutura de organização de ações contra desastres. Entretanto, de acordo com o Major são poucos os municípios que a Defesa Civil realmente funciona. Para que a COMDEC esteja funcionando, é preciso "[...] fazer investimento através da Prefeitura, para que a COMDEC possa trabalhar durante o ano inteiro: ação de prevenção e preparação $[\ldots] "$ ". 


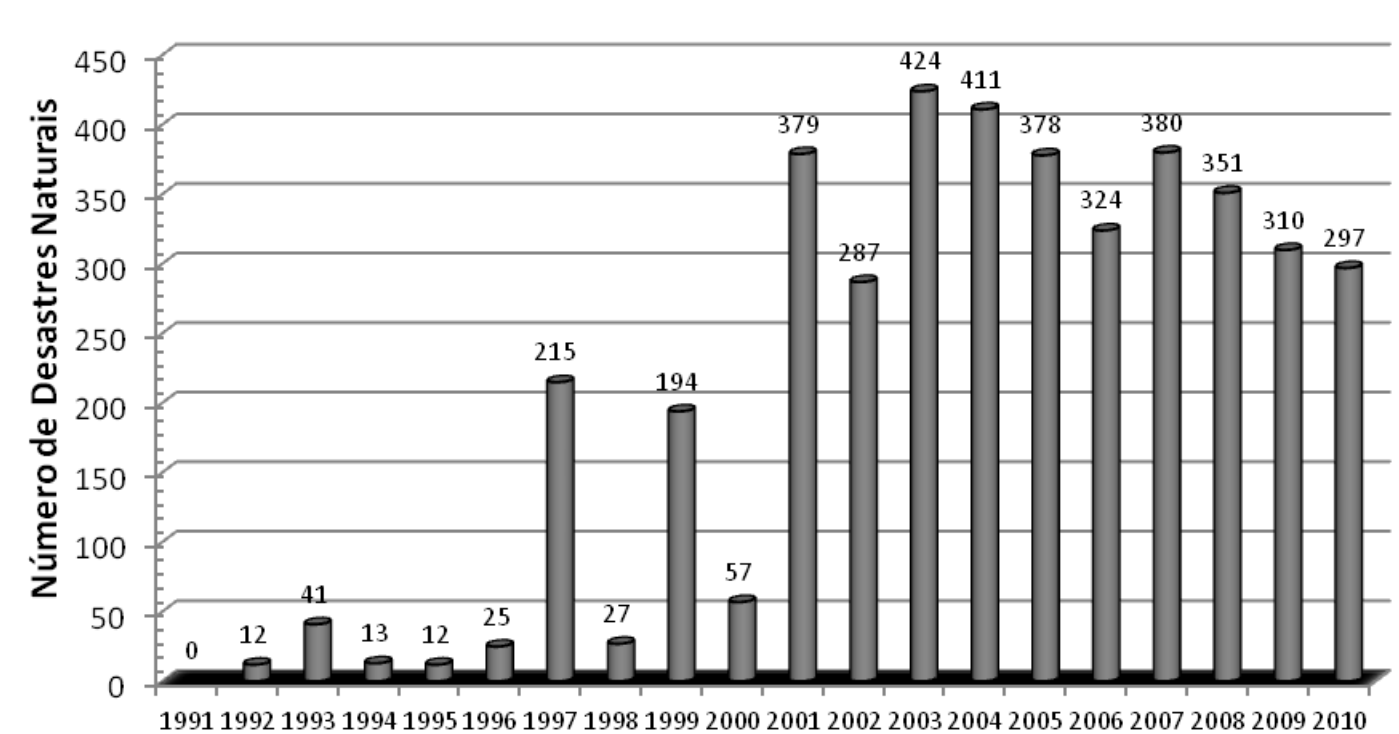

Figura 4, Registros anuais do número de desastres naturais entre 1991 a 2010, no Estado de Minas Gerais.

Fonte: Atlas de Desastres Naturais de Minas Gerais (2012).

Assim, quando "[...] a Defesa Civil é bem estruturada, ela consegue atuar de uma maneira que a comunidade não sofra tanto, não venha a ter tantos prejuízos [...]" (ABREU, CEDEC/MG, 02/09/2009). Assim, em cidades como Caratinga, em que há investimentos em Defesa Civil, foram colocadas sirenes em três pontos altos da cidade. Quando a situação é muito crítica, as mesmas são acionadas. Além disso, a população é treinada e instruída par onde se direcionar, quando o artefato sonoro for acionado.

Segundo Nascimento (2009) observou que dentre as maiores dificuldades de implementação de uma COMDEC, deve-se à vontade política do Prefeito. Os governantes municipais acreditam que a Defesa Civil não seja necessária, pois não elege, e por isto não investem nela. Somente quando acontecem grandes tragédias é que percebem a necessidade deste órgão.

A CEDEC/MG auxilia os municípios através de cursos de capacitação dos agentes envolvidos nas atividades de Defesa Civil, além de apoiar durante o período de normalidade, ensinando como proceder por ocasião dos desastres. Assim, as ações de prevenção são de responsabilidade da COMDEC, somente depois que acontecem os desastres é que a CEDEC/MG atua no município, mesmo assim, quando soclicitada.

Deste modo, a COMDEC deve trabalhar primeiramente a prevenção e preparação, que se fundamenta em dois pilares: mapeamento das áreas de risco e execução de um plano de contingência (um planejamento das ações de cada setor da Prefeitura, bem como o treinamento e preparação da comunidade quando o desastre vir a acontecer).

Posteriormente, devem ser trabalhadas as ações de resposta e reconstrução posteriormente a ocorrência do desastre. Em virtude do desastre a COMDEC deve enviar à CEDEC/MG o NOPRED e o AVADAN como forma de respaldar o decreto de SE ou ECP, que são essenciais para a liberação de recursos para a reconstrução do município.

Todavia, o envio da documentação do NOPRED e AVADAN, esbarra, muitas vezes, na ausência de profissionais treinados e preparados para agirem de imediato a situações extremas. 
Isso por sua vez, acarreta distorções, pois os municípios mais atingidos e, por conseguinte o mais vulnerável é aquele que não conseguirá a homologação da situação de emergência, ao nível estadual e muito menos, o reconhecimento da condição de fragilidade ao nível federal. Tal fato dificulta o processo de obtenção de recursos para reconstrução das áreas atingidas.

Contudo, isso não significa que, caso o município obtenha êxito no trâmite processual, que o mesmo consiga a liberação do recurso tão facilmente, mesmo com os projetos das obas em mãos. Também dependerá da força política dos deputados federais e estaduais que representam os municípios afetados, e de um projeto técnico específico para a reconstrução das áreas afetadas.

Nesse contexto, vale relembrar que dezembro de 2008 o índice pluviométrico de Minas Gerais foi considerado excepcional, principalmente, na Zona da Mata e Região Central (30\% acima da média histórica), conforme Nascimento (2009), Silva (2009) e Fialho et. al. (2010), verificaram respectivamente para os municípios de Piranga, Ponte Nova e a bacia do rio Piranga, na região do alto rio Doce (Figura 5 e 6), muitos municípios foram acometidos por problemas de enchentes bruscas, porém apenas 39 comunicaram, outros demoraram a entrar em contato com a CEDEC-MG, e outros o fizeram de maneira inadequada. Por isto, o número de municípios amparados pela CEDEC-MG em 2008 foi relativamente pequeno se comparado à intensidade do evento pluvial, apenas 100 homologações, número menor do que 2001/2002.

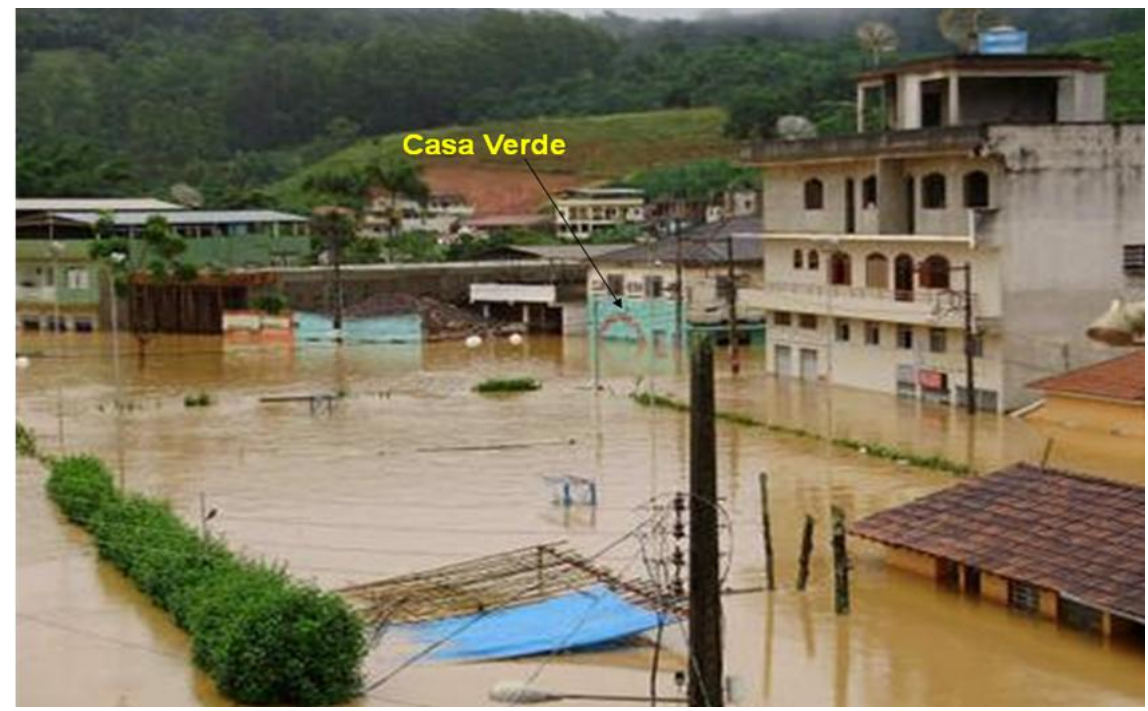

Figura 5. Praça central de Porto Firme submersa após as chuvas entre os dias 17 e 18 de dezembro de 2008.

Fonte: Jornal O Tempo do dia 18 de dezembro de 2008. 


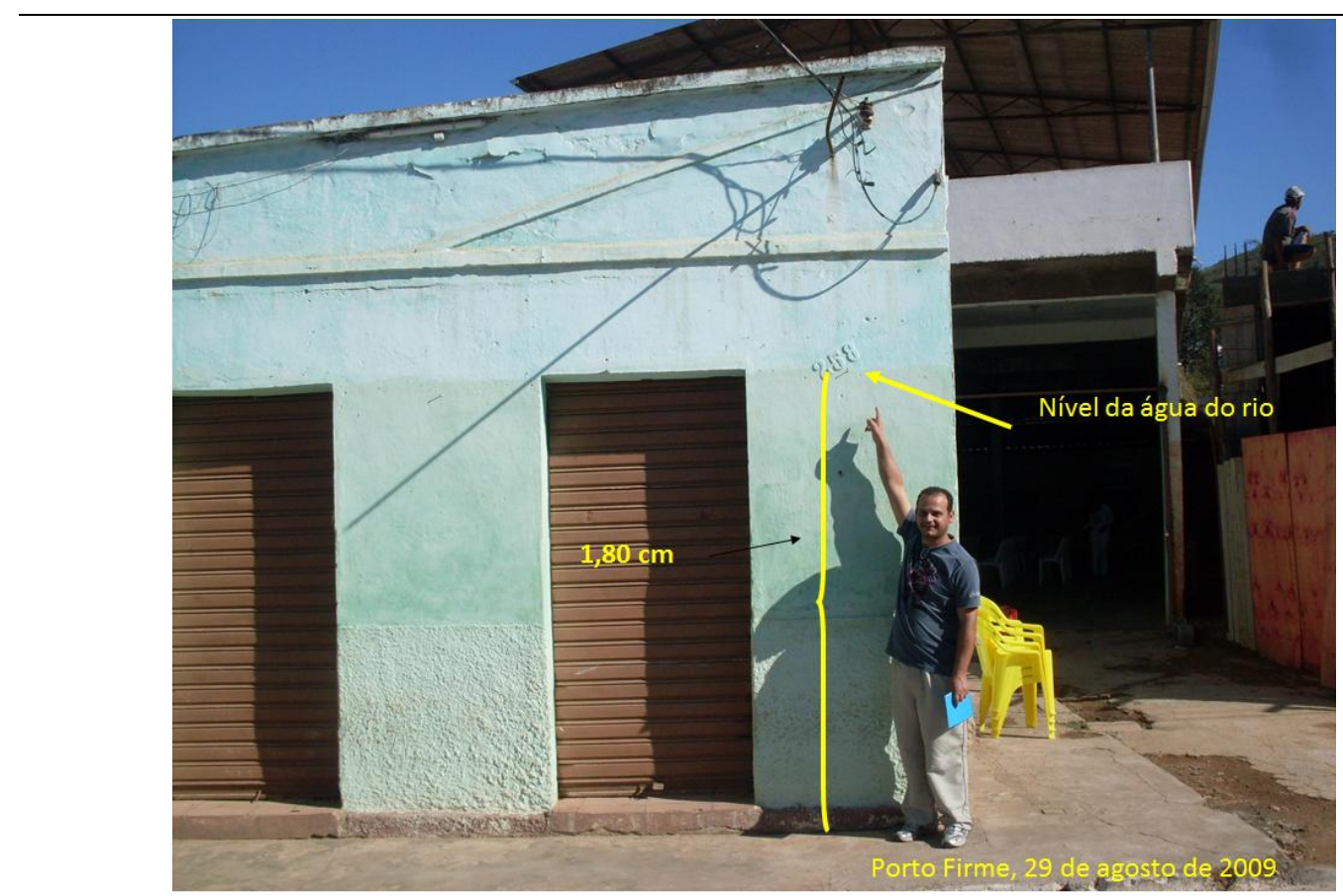

Figura 6. Imagem que mostra até onde chegou o nível do rio Piranga, na casa verde identificada na Figura 5, situada na Praça de Porto Firme.

Fotografia obtida por Edson Soares Fialho em 29 de agosto de 2009.

Uma forma de alerta que a CEDEC-MG utiliza é a parceria com MG Tempo CEMIG/PUC-Minas, em que há a previsão de quais áreas do Estado podem ter chuvas torrenciais. Com base nesta previsão este órgão faz o alerta através dos meios de comunicação, ou mesmo estabelece contato com as COMDEC's, Polícia Militar, Bombeiros, e Prefeituras (quando a cidade não possuiu COMDEC).

Além desse mecanismo, há o sistema de alerta contra cheias da Bacia do Rio Doce (Figura 7), que está integrado ao Sistema de Meteorologia e Recursos Hídricos de Minas Gerais (SIMGE) e ao Instituto Mineiro de Gestão das Águas (IGAM), que divulga pela internet as informações sobre a vazão dos rios da bacia hidrográfica do rio Doce, criado após o evento de 1978-1979, (Figura 8).

Contudo, as Prefeituras que possuem uma COMDEC e são bem estruturadas não precisam desse tipo de alerta, pois as próprias coordenadorias buscam as informações, uma vez que elas têm parceria direta com o Instituto de Meteorologia, como Muriaé e Caratinga, que contam com seu próprio sistema de alerta. Mesmo assim, a CEDEC/MG avisa aos municípios, cabendo a estes repassar o aviso de alerta à população, o que nem sempre ocorre. 


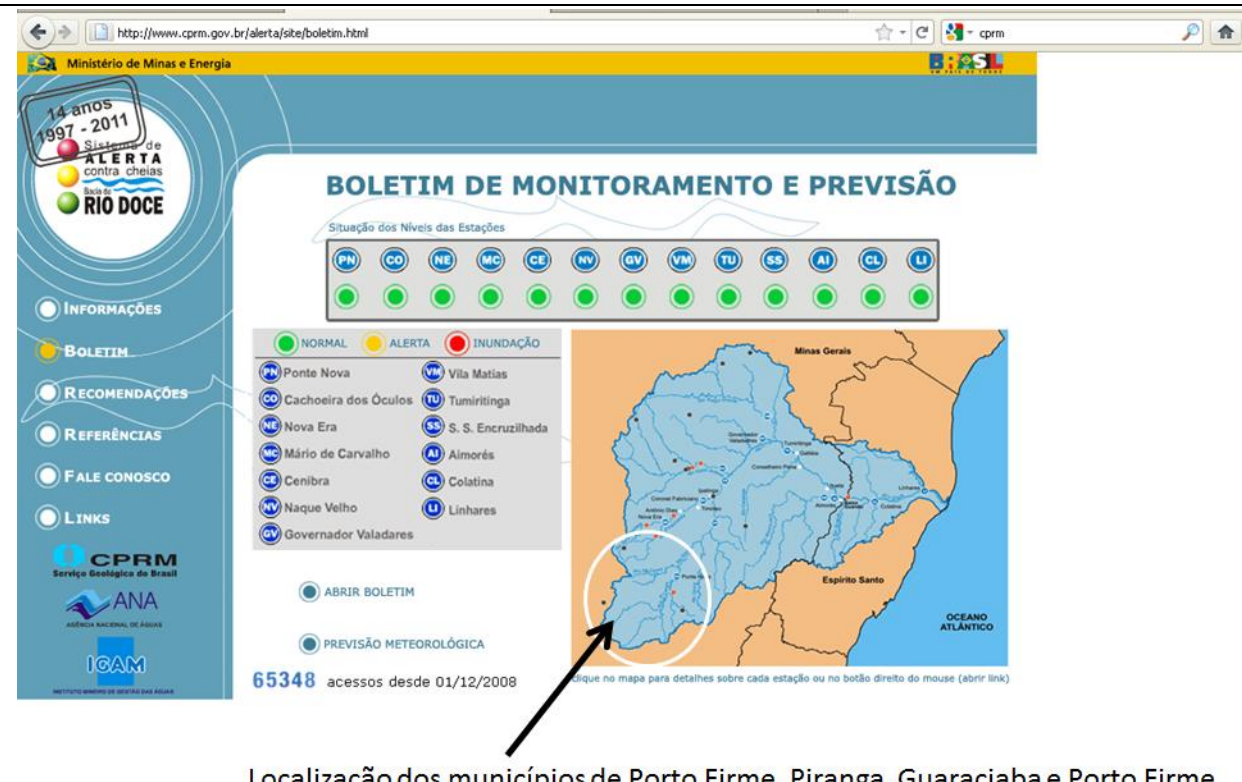

Figura 7. Sítio do Sistema de Alerta contra Cheias da Bacia do Rio Doce (Disponível em: http://www.cprm.gov.br/alerta/site/boletim.html).

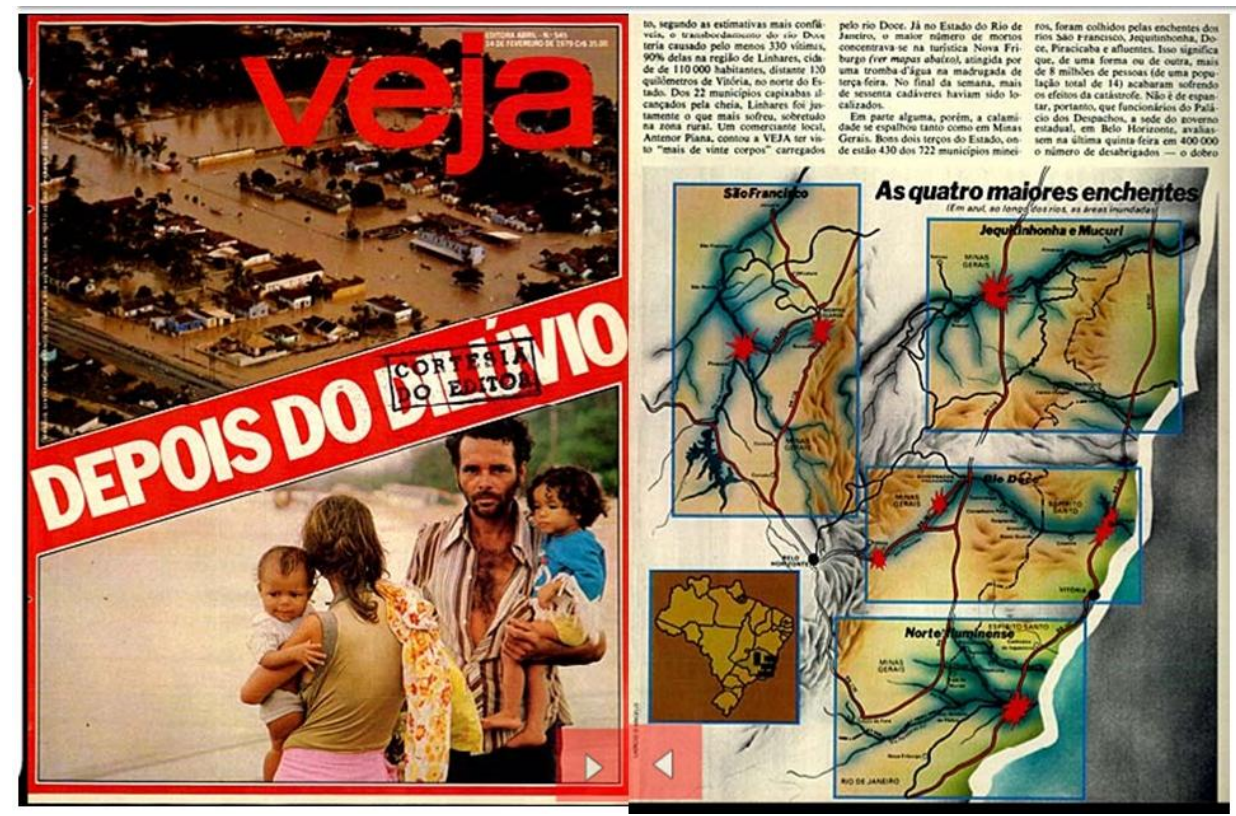

Figura 8. Capa da revista Veja sobre as chuvas intensas no vale do rio Doce entre dezembro de 1978 e janeiro de 1979.

Fonte: Disponível em: http://veja.abril.com.br/acervo/. Acesso em 28 mar. 2013.

Quando o município não está estruturado para enfrentá-lo e não realiza treinamentos periódicos junto à população, estes eventos podem se tornar tragédias, conforme observaram Maia e Pitton (2009) para a cidade de Ribeirão Preto.

Esta capacidade de resposta do município no que tange aos desastres é um dos itens presentes no AVADAN. Assim, em virtude do despreparo ou da inexistência da COMDEC e da 
própria vulnerabilidade do cenário, alguns desastres considerados normais, passam a ser alarmantes sendo preciso decretar SE, como o ocorrido no município de Piranga em virtude da inundação ocorrida em dezembro de 2008:

[...] numa cidade como BH não há necessidade de decretar uma situação de emergência, como em Caratinga, pois as pessoas estão mais orientadas. Então, depende muito da vulnerabilidade do cenário e o preparo do poder público no desastre [...] o rio encheu alagou tudo ali ao redor, se fosse avisado os estragos seriam menores, mas depois ele abaixa e volta ao curso normal. Se a cidade está muito bem preparada, isto é uma coisa normal, Valadares todo ano, Ponte Nova todo ano, até acontecer o ano passado, já é esperado. As pessoas já sabem que têm que construir uma sobreloja, ou seja, já sabe que vai ser alagado [...] A capacidade de resposta que é um dos atos que tem aqui no AVADAN, quando agente vai verificar, despreparo da Defesa Civil local e vulnerabilidade do cenário, então o desastre daquele de Piranga que aconteceu, tinha que ter decretado SE, por quê? Por causa do despreparo, enfim de uma série de fatores. Mas numa cidade como BH não precisava decretar, ou igual à Caratinga, as pessoas já estão acostumadas. Então, depende muito da vulnerabilidade do cenário e o preparo do poder público no desastre [...] (ABREU, CEDEC/MG, 02/09/2009).

Atualmente, os prefeitos não decretam ECP pelo fato de que a população da área afetada poder solicitar o ressarcimento dos impostos municipais, ou até mesmo estaduais e federais, por vias judiciais. Sabendo disto, os prefeitos só decretam SE, em casos extremos como o de Santa Catarina ocorrido em 2008, quando foi decretado ECP para facilitar a liberação de recursos federais para a reconstrução.

\section{CONSIDERAÇÕES FINAIS}

Após a apresentação do processo legal de obtenção dos recursos públicos, pode-se dizer que, as COMDEC's, juntamente com o Poder Público local, atuam de maneira ineficiente, mesmo com todo o apoio dado pela CEDEC-MG no sentido de preparar os municípios para receber os eventos climáticos ou mesmo frente aos avisos de previsão meteorológica no sentido de se, alertar a população.

Assim sendo, muitos são os municípios mineiros afetados por eventos catastróficos no decorrer do ano. Porém, a maioria dos municípios não está preparada para contornar os problemas decorrentes de tais eventos. Entretanto, mesmo frente aos prejuízos e danos, muitos municípios afetados não decretam $\mathrm{SE}$, e tão pouco comunica o fato ocorrido à CEDEC/MG, o que demonstra um despreparo e descaso do Poder Público local, além, da ausência e precário funcionamento da COMDEC. Aliado a isto, a não decretação de ECP revela que o Poder Público está mais preocupado com as questões econômicas no que tange a arrecadação de impostos, do que com as questões sociais que se referem aos prejuízos e danos materiais e mesmo humanos relacionados à população afetada.

Assim sendo, ao analisar somente os municípios que decretaram SE, percebe-se que a demanda por recursos em Minas Gerais é notável. Entretanto, devido a não observação da 
documentação necessária e dos prazos estipulados por parte do Poder Público local, aliada a burocracia e trâmites legais, os recursos para reconstrução não são liberados.

Por outro lado, aqueles municípios que seguem corretamente todos os passos, precisam elaborar bons projetos e ter força política para usufruir dos recursos necessários à reconstrução, que podem levar anos para serem liberados. Caso contrário, os problemas sempre retornarão, como uma crônica de uma morte anunciada, onde no campo do embate fora da dimensão política, os citadinos podem ser levados olhar com simpatia posições políticas desagregadores, colocando a responsabilidade dos problemas apenas em um setor da sociedade, geralmente, as vítimas, que nunca irão aceitar tal posição e com isso os atritos poderão criar um acirramento de uma situação de tensão política instalada, que acaba por aumentar os problemas, geralmente, socializados de maneira desigual.

Embora a prática política brasileira tenha seus vícios, é necessário que a população se envolva mais nas discussões dos planos diretores das cidades, a fim de que possa haver a possibilidade o espaço de novas possibilidades de soluções, que perpassam pelo caminho da convergência de interesses e não por soluções mágicas e personificadas.

\section{AGRADECIMENTOS}

Inicialmente, gostaria de agradecer a Professora Ana Valéria Freire Allemão Bertolino e Luiz Carlos Bertolino pela organização do II Seminário de Geografia: Dinâmica das Paisagens, que faz parte das atividades do Grupo de Pesquisa Dinâmica das Paisagens, que iniciou suas atividades na Universidade Federal de Viçosa-UFV, onde reuniram pesquisadores da UFMG, UFES, UERJ-FFP, UFF e UFV para agregar as pesquisas desenvolvidas e potencializar a produção de uma linha até então pouco valorizada no cenário geográfico, mesmo com tanta visibilidade em questões de desastres naturais, catástrofes e processos naturais e suas influências sobre os grupos humanos. A vocês o meu muito obrigado!!!

Além dos professores, gostaria também de agradecer aos mestrandos, bolsistas de iniciação científica, extensão universitária e os voluntários do Laboratório de Geociências da UERJ-FFP, que muito auxiliaram no desenrolar das atividades. Sem vocês o evento não se concretizaria. Muito Obrigado!!!

Aos bolsistas e voluntário do Laboratório de Biogeografia e Climatologia (Bioclima), a qual coordeno e oriento as pesquisas desenvolvidas pelos acadêmicos, que resolveram investir na Geografia Física como uma possibilidade de crescimento profissional.

A minha esposa Edmar Maria (Nega), minha filha Letícia Maria (Preta) e meu filho Samuel (Preto), que convivem com minha distância e ausência em muitos momentos, em razão do trabalho, o muito obrigado por vocês existiram. Sem vocês eu nada seria.

\section{NOTAS}

1 - Palestra proferida na mesa redonda intitulada: A climatologia e as dinâmicas ambientais, proferida no II Seminário de Geografia: Dinâmica das Paisagens, realizado entre os dias 5 e 6 de dezembro de 2012, no campus da Faculdade de Formação de Professor da Universidade do Estado do Rio de Janeiro, em São Gonçalo

2 - Ver tabelas de critérios para decretar estado de calamidade ou situação de emergência no site http://www.defesacivil.gov.br 
3 - Ver endereço eletrônico

http://defesacivil.gov.br/docs/situacao/Formulario_NOPRED_AVADAN.doc>

\section{REFERÊNCIAS}

ABREU, M. L. Climatologia da estação chuvosa e Minas Gerais: de Nimer (1977) à Zona de Convergência do Atlântico Sul. Geonomos, Belo Horizonte, v. 4, n. 2, p. 17-22, 1998.

ATLAS BRASILEIRO DE DESASTRES NATURAIS - 1991 a 2010: volume Minas Gerais / Centro Universitário de Estudos e Pesquisas sobre Desastres. Florianópolis: CEPED UFSC, 2011.

BERGAMO, E. P.; ALMEIDA, J. A. P. A importância da Geomorfologia para o planejamento ambiental: Um estudo do município de Fartura-SP. In: SIMPÓSIO NACIONAL DE GEOMORFOLOGIA, 6, 2006. Anais..., Goiás. 2006.

BARRETO, J. R. Impactos Pluviais: Um estudo de caso de Jacareí-SP. 90f. Dissertação (Monografia em Geografia). Curso de Geografia. Departamento de Geografia, UFV-MG, Viçosa-MG, 2012. Disponível em: http://www.geo.ufv.br/monografias/2012I/Julia\%20de\%20Rezende\%20Barreto.pdf. Acessa em 30 mar. 2013.

BRANDÃO, A. M. P. M. As alterações climáticas na área metropolitana do Rio de Janeiro: Uma provável influência do crescimento urbano. In: ABREU, M. A. (org.).: Natureza e Sociedade no Rio de Janeiro. 3ed. Rio de Janeiro: Secretaria Municipal de Cultura, Turismo e Esportes/Departamento Geral de Documentação e Informação Cultural, 1992, p. 143-191.

As chuvas e a ação humana: uma infeliz coincidência. in: ROSA, L. P.; LACERDA, W. A. (orgs).: Tormentas Cariocas. Rio de Janeiro: Coppe-UFRJ, p. 21-37, 1997.

Clima Urbano e Enchentes na cidade do Rio de Janeiro. In: GUERRA, A. J. T. e CUNHA, S. B. (orgs.): Impactos Ambientais Urbanos no Brasil. Rio de Janeiro: Bertrand, 2005, p. 47-109.

FIALHO, Edson Soares, BRANDÃO, Ana Maria de Paiva Macedo. As Chuvas e a (Des) Organização do Espaço Urbano Carioca. Revista Geouerj. Rio de Janeiro, v. 4, n. 8, p. 39-53, 2000.

FIALHO, E. S.; VIEIRA, J. C. R.; MACHADO, D. V.; SILVA, A. P. R.; FREIRE, R. G. Enchentes, meio ambiente e planejamento: Um estudo de caso no município de Duque de Caxias. In: OLIVEIRA, R. S. (org.).: Baixada Fluminense: Novos estudos e desafios. Rio de Janeiro: Paradigma, 133-147p, 2004.

FIALHO, E. S.; NASCIMENTO, R. A.; SILVA, C. H.; SILVA, L. O. Compreendendo a dinâmica das enchentes e suas repercussões no médio e baixo vale da bacia hidrográfica do rio Piranga em dezembro de 2008. In: SIMPÓSIO BRASILEIRO DE CLIMATOLOGIA GEOGRÁFICA, 9, 2010. Ceará, Anais..., Fortaleza: ABCLIMA/UFC, 2010, cd-rom. 
FIALHO, E. S. Uma avaliação do caminho dos recursos públicos federais entre os estados de Minas Gerais e do Rio de Janeiro frente a eventos climáticos extremos. In: ENCONTRONACIONAL DA ASSOCIAÇÃO DE PÓS-GRADUAÇÃO E PESQUISA EM GEOGRAFIA, 9, 2011, Goiânia, Anais..., Goiás, 2011. cd-rom.

FIALHO, E. S.; COELHO, D. D. A destinação de recursos públicos para a minimização dos impactos decorrentes de eventos pluviais extremos nos estados de Minas Gerais, Santa Catarina e São Paulo entre 2008 e 2010. Revista Acta Geográfica, Boa Vista, v. 4, n. 8, p. 67-82, 2011.

FIALHO, E. S. A dinâmica plúvio-financeira no estado do Rio de Janeiro. Revista de Ciências Humanas, Viçosa, v. 12, n. 1, p. 181-201, 2012a.

FIALHO, E. S. O clima e a gestão do território: O papel da Defesa Civil no processo de reconstrução das áreas atingidas por eventos atmosféricos extremos. Revista Entre-Lugar, Dourados, v. 3, n. 6, p. 85-108, 2012 b.

FRAGA, N. As enchentes no Vale do Itajaí - Açú/SC: das obras de contenção à indústria da enchente: a problemática ambiental e a relação homem/natureza na busca de soluções. Revista RA'EGA - O Espaço Geográfico em Análise, Curitiba, v. 5, n. 1, p. 135-148, 2005.

GONÇALVES, N. M. S. Impactos pluviais e desorganização do espaço urbano de Salvador. In: MONTEIRO, C. A. de F; MENDOÇA, F. (orgs.).: Clima Urbano. São Paulo: Contexto. 2003. p. 69-91.

GONTIJO, B. M.; ASSIS, W. L. Análise preliminar da sucessão de tipos de tempo no norte de Minas gerais e suas relações com os sistemas atmosféricos atuantes: Períodos chuvosos de 1978/1979 e 1984/1985. Geonomos, Belo Horizonte, v. 5, n. 2, p. 59-64,1997.

GRELLET, F. Apesar das chuvas, região serrana recebe menos verba federal que o Rio. Jornal O Estado de São Paulo. Caderno Brasil. São Paulo, 19 de março de 2013. Disponível em: http://www.estadao.com.br/noticias/cidades, apesar-das-tragedias-regiao-serrana-recebe-menosverba-federal-que-o-rio, $1010802,0 . \mathrm{htm}$

LIMA, L. C.; ZANELLA, M, E. A climatologia aplicada ao planejamento urbano e ambiental de Aquirraz-CE. Revista Geográfica de América Central, Costa Rica, v. 2, n. 47, 13p. 2011.

MAIA, D.; PITTON, S. E. Caracterização das enchentes na área urbana de Ribeirão Preto (SP): Um enfoque através das notícias de jornal. Revista Geografia, Rio Claro, v. 34, n. 2, p. 307-327, 2009.

NASCIMENTO, R. A., FIALHO, E. S. Análise do processo de reconstrução após o período chuvoso, nos municípios de Minas Gerais entre 2006 e 2009. In: ENCONTRO MINEIRO DE ADMINISTRAÇÃO PÚBLICA: Economia Solidária e Gestão Social, 2, 2009, Viçosa. Anais..., Minas Gerais: UFV, 2010, cd-rom. Disponível em: <http://www.emapegs.ufv.br/docs/Artigo08.pdf>. Acesso em 3 mar. 2013. 
NASCIMENTO, R. A. Análise dos impactos e repercussões do evento pluvial no município de Piranga-MG, em 17 dezembro de 2008. 129f. Dissertação (Monografia em Geografia). Curso de Geografia. Departamento de Geografia, UFV-MG, Viçosa-MG, 2009. Disponível em: http://www.geo.ufv.br/monografias/monografias2009-2/RosileneAparecidadoNascimento.pdf. Acessa em 30 mar. 2013.

NASCIMENTO, R. A. Impactos pluviais: O caso de Piranga-MG. Revista de Ciências Humanas, Viçosa, v. 10, n. 1, p. 94-110, 2010. Disponível em: http://www.cch.ufv.br/revista/pdfs/artigo6vol101.pdf. Acesso em 29 mar. 2013.

MAIA, D. C.; PITTON, S. C. E. Caracterização das enchentes na área urbana de Ribeirão Preto (SP): um enfoque através das notícias de jornal. Revista Geografia, Rio Claro, v. 34, n. 2, p. 307-327, 2009.

PENHA, H. M. A importância da Geomorfologia no planejamento ambiental: Uma breve apreciação. Revista do Instituto de Geociências da UFRJ, Rio de Janeiro, v. 15, p. 163-165, 1992.

PORTAL DA DEFESA CIVIL DE MINAS GERAIS. Disponível em: <http://www.defesacivil.mg.gov.br>. Acesso em: 17 de set. de 2009.

PORTAL DA TRANSPARENNCIA NOS RECURSOS PÚBLICOS FEDERAIS. Disponível em: $<$ http://www.portaltransparencia.gov.br>. Acesso em: 24 de mar. de 2010.

SANT'ANNA NETO, J. L. Decálogo da climatologia do sudeste brasileiro. Revista Brasileira de Climatologia, Presidente Prudente - São Paulo, v. 1, n. 1, p. 43-60, 2005.

SÁNCHEZ V. A. Convite à Estética. Rio de Janeiro: Civilização Brasileira, 1999.

SECRETARIA NACIONAL DE DEFESA CIVIL. Disponível em: <http://www.defesacivil.gov.br>. Acesso em: 16 de maio de 2009.

SILVA, L. A. O.A desorganização do espaço urbano em Ponte Nova (MG) frente às grandes enchentes de 1951, 1979, 1997 e 2008. 66f. Dissertação (Monografia em Geografia). Curso de Geografia. Departamento de Geografia, UFV-MG, Viçosa-MG, 2009. Disponível em: http://www.geo.ufv.br/monografias/monografias2009-2/LeonardoAlvesdeOliveira.pdf. Acesso em 28 mar. 2013.

STERNBERG. H. R. Enchentes e movimentos coletivos do solo no Vale do Paraíba em dezembro de 1948 - Influência da explotação destrutiva das terras. Revista Brasileira de Geografia. Rio de Janeiro, v. 11, n. 2, p. 223-262, 1949. 